\title{
A normatização do cuidar da criança menor de um ano: estudo dos significados atribuídos pelos profissionais do Programa Saúde da Família (PSF)
}

\author{
The normative of the caring on children above one-year-old: \\ a study of meanings applied by the professionals \\ of Family Health Program (FHP)
}

Eliane Nóbrega Vasconcel os ${ }^{1}$

Maria de Fátima Araújo da Silveira ${ }^{2}$

Maria do Carmo Eulálio ${ }^{3}$

Paula Frassinetti Vasconcelos M edeiros ${ }^{4}$

\footnotetext{
${ }^{1}$ Departamento de

Fisioterapia, Centro de

Ciências Biológicas e da

Saúde, Universidade

Estadual da Paraíba. Av. das

Baraúnas 351, Bodocongó.

58109-753 Campina

Grande PB.

elynobrega@terra.com.br

${ }^{2}$ Departamento de

Enfermagem, Centro de

Ciências Biológicas,

Universidade Estadual da

Paraíba.

${ }^{3}$ Departamento de

Psicologia, Centro de

Ciências Biológicas,

Universidade Estadual da

Paraíba.

${ }^{4}$ Unidade Acadêmica de

M edicina, Centro de

Ciências Biológicas e da

Saúde, Universidade

Federal deCampina

Grande.
}

Abstract TheFamily H ealth Program was implanted as a change strategy and reorganization of the assistance model, aiming to overcome the fragmentation of care and, then, proposes a quality, humanitarian integral attending. The objective of this work is to identify how children under one-year-old have been cared by professionals of FHP. The study has a qualitative approach, and data was produced in four creative and sensitive workshops. The workshops were taped and transcribed. After that, the observations of the participants were submitted to an analysis. The results demonstrated that the under one-year-old children care has been normative at most. The UBSF researched had no proper environment or instrument for children's assistance. The professionals have an improper academic formation and they hadn't been receiving continuous training capable to can act with this age group. Also, there is a huge difficult on facing social and cultural differences on the conduction of medium and high complexity procedures. $\mathrm{N}$ evertheless, professionals consider their work dynamic and challenger, and that their actions have been contributing a lot to children's health. Key words To care, Children, Family Health Program
Resumo O PSF foi implantado como uma estraté gia de mudança e reordenamento do modelo assistencial, visando a superar a fragmentação do cuidado e, para tanto, propõeum atendimento integral, de qualidade e, sobretudo, humanizado. Este trabalho teve por objetivo identificar como vem sendo cuidada a criança menor de um ano pelos profissionais do PSF. 0 estudo tem abordagem qualitativa eos dados foram produzidos no contexto de quatro oficinas de sensi bilização e criatividade, cujo conteúdo gravado foi tranर्sformado em corpus de discursos, e registros da observação participante, submetidos à análise de conteúdo. O sresultados demonstraram que o cuidado ao menor de um ano tem sido majoritariamente normativo, as UBSF pesquisadas não possuem ambiente e instrumental adequado para 0 atendimento de crianças, a formação acadêmica dos profissionais é inadequada e estes não têm recebido capacitação continuada para atuação nesta faixa etária. Há, ainda, enormes dificuldadesno enfrentamento dasquestões sociais e culturais e nos encaminhamentos para procedimentos de média e alta complexidade. No entanto, os profissionais consideram o trabalho dinâmi co e desafiador e, com as suas ações, muito têm contribuído para a saúde das crianças cuidadas. Palavras-chave Cuidar, Criança, Programa Saúde da Família 


\section{Introdução}

Este artigo é parte integrante da dissertação de mestrado "O cuidar da criança menor de um ano pelo Programa Saúde Família (PSF): discurso e prática dos profissionais da equipe", apresentada ao mestrado em saúde coletiva, da Universidade Estadual da Paraíba. 0 estudo teve como ponto de partida a vivência docente e assistencial, ao nos depararmos, constantemente, no ambulatório de referência para intervenção precoce de crianças com transtornos no desenvolvimento do Instituto de Saúde Elpídio de Almeida (ISEA), em Campina Grande (PB), com encaminhamentos recebidos da atenção básica, de desvios no desenvolvimento da criança, detectados tardiamente, diminuindo as chances de habilitação funcional, e, ao mesmo tempo, com mães alheias ao problemaedesprovidas deorientações antecipatórias.

Diante desta realidade, surgiram os seguintes questionamentos: como está sendo cuidada a criança menor de um ano nas unidades de Saúde da Família? Quais as estratégias e os instrumentos utilizados pelas equipes do PSF para prestar-Ihe uma assistência integral e humanizada? Qual a sistematização do cuidado ao menor de um ano? Para responder a estas indagações, foi delimitado como objetivo da pesquisa analisar o cuidar da criança menor de um ano no PSF em Campina Grande, Paraíba, N ordeste, Brasil.

Partimos do pressuposto de que os olhares direcionados à criança vêm sofrendo grandes transformações devido às influências de cada período histórico, aos avanços nos conhecimentos técnicocientíficos, às diretrizes das políticas públicas e ao desenvolvimento e participação de vários agentese segmentos da sociedade. Entretanto, vale ressaltar que, essa conduta é relativamente recente. Nos livros de história da civilização, a criança costuma estar quase sempre ausente, como se não fizesse parte da humanidadel. É possível constatar que, quanto mais se caminha para o passado, mais expostas as crianças estão à morte violenta, ao abandono, ao espancamento, ao abuso sexual e ao baixo nível de assistência². No entanto, devido à reformulação nos conceitos do que éser criança, à instituição de novas leiseà melhora naqualidadeeacesso aos serviços de saúde, pode-se observar que houve melhora na situação infantil, no Brasil e no mundo. Porém, ela continua sendo vítima dos desajustes estruturais, sociais e políticos da sociedade.

M ovimentosmundiais pelainfânciavêm lutando para que a criança realize a finalidade da criatura humana que ela é, que seja reconhecida como pessoa, como cidadã. Num desses movimentos, ocorrido em 1959, naAssembléia Geral das Nações Unidas, foi aprovada, por unanimidade, a Declaração dos Direitos da Criança. Nela, enumeraram-se os direitos eliberdades a que, segundo o consenso da comunidade internacional, faz jus toda e qualquer criança. 0 documento expressa que a criança, em decorrência de sua imaturidade física e mental, requer proteção e cuidados especiais, antes e depois do nascimento.

A Constituição Federal do Brasil, de 1988, garantiu a atenção à saúde como um direito universal e dever do Estado e, para isto, foi criado o Sistema Ú nico de Saúde (SUS). Em 1990, o Estatuto da Criança e do Adolescente assegurou, legalmente, a cidadania como um direito da criança e a sua promoção, como um dever do Estado e da sociedade. No âmbito da saúde, ficou acordado que, além dese oferecer um atendimento indiscriminado, a pessoa deve ser tratada na sua individualidade. N este contexto, muitas ações vêm sendo realizadas pelo M inistério da Saúde, com o intuito de aumentar 0 acesso, melhorar a qualidade e humanizar a assistência prestada à criança, dentre as quais se destacam a estratégia de Atenção Integrada às Doenças Prevalentes na Infância (AIDPI) eo Programa Saúdeda Família (PSF), quefoi implantado no Brasil em 1994, com o objetivo de substituir o modelo de atenção, atéentão de caráter eminentemente assistencialista, curativo, médico-centrado, medicalizante e hospitalocêntrico ${ }^{3}$.

Entretanto, na atenção básica falta um esquema metodológico de exame do desenvolvimento neurológico infantil adequado para o acompanhamento sistemático da criança. Assim, como ressalta Jerusalinsk ${ }^{4}$, "ainda há muito a ser feito no sentido de uma política de saúde eeducação que privilegie a intervenção e detecção precoce de problemas na constituição psíquica e do desenvolvimento da criança". Alguns autores ${ }^{5}$ defendem ser possível aperfeiçoar 0 atual modelo assistencial, de vigilância à saúde, no sentido de potencializar o uso dos recursos existentes, visando a humanizar e qualificar a atenção prestada.

A criança, em seu primeiro ano devida- o bebê -, devido a sua vulnerabilidade, é classificada como grupo de alto risco, tornando-se prioritária nas ações de saúde. Neste período, cada mês e cada fase de desenvolvimento acarretam implicações para a sua assistência. N esse contexto, cuidar de uma criança significa colocar-se num campo de alta complexidade, devido à vasta rede conceitual quea representa, ondeinumeráveis entrecruzamentos levam-nos a considerar não apenas a sua sobrevivência, mas, principalmente, o seu desenvolvimento, o seu bem-estar e sua qualidade de vida e a ressignificar o cuidado a ela oferecido.

0 movimento da medicina social ${ }^{6}$, as análises sobre as sociedades tradicionais e sobre o lugar da 
criança e da família nas sociedades industriais ${ }^{1}$ e as fundamentações teóricas sobre a pediatria preventiva, clínica, cirúrgica, neonatal esocial ${ }^{7}$ trouxeram contribuições essenciais para repensar o cuidado com a criança.

As palavras cuidar, cuidado e cuidador têm sido muito utilizadas, exatamenteporquehojeconhecemos os resultados que a ausência de cuidado, em suas mais diferentes formas, deixa como marca em tudo que vive e existe. 0 cuidado é uma parte integral da vida e nenhum tipo de vida pode subsistir sem ele ${ }^{8}$. Os bebês mostram de forma muito clara a sua necessidade e dependência do cuidado.

A estratégia Saúde da Família vem realizando esforços para a modificação do processo de cuidado, revisitando conceitos fundamentais de víncuIo, respeito, humanização, climatização, co-responsabilidade ${ }^{9}$, entre outros, apontando para a reorientação do modo de operar os serviços de atendimento, visando a incrementar a capacidade resolutiva dos serviços de saúde na atenção à criança. Contudo, existem, notadamente, espaços a serem preenchidos entre a prescrição normativa e a operacionalização no cotidiano dos serviços.

Muitas pesquisas vêm buscando e experimentando novos enfoques e estratégias para investigar o fenômeno cuidar/cuidado ealgumas críticas apontam para a necessidade de expandir e aprofundar vários aspectos, no sentido de contribuir com 0 ensino e a reorganização das instituições que prestam assistência à saúde ${ }^{10}$. Ressal te-se que, na literatura pesquisada, existem poucos trabal hos relacionados à atenção integral, humanizada e sistemática à criança menor de um ano, bem como não há, ainda, estudo enfocando o modo pelo qual tem se processado as experiências vividas nas Unidades Básicas de Saúde da Família de Campina Grande.

\section{M etodologia}

0 método de estudo teve natureza qualitativa do tipo exploratório, transversal e descritivo-analítico.

O cenário do estudo foi o município deCampina Grande, onde, oficialmente, existem 49 bairros, além dos distritos rurais deCatolé de Boa Vista, Catolé de ZéFerreira, São José da M ata, Santa Terezinha e Galante. A cidade polariza uma área de cinco microrregiões homogêneas, num total de $23.960 \mathrm{~km}^{2}$, correspondente a $43 \%$ do território paraibano e $40 \%$ da população do estado. Sua área territorial é de 621 $\mathrm{km}^{2}$. Fica a 120 quilômetros da capital do estado, João Pessoa, no agreste paraibano, a uma altitude média de 552 metrosacima do nível do mar. 0 município é considerado um dos principais pólos industriais e tecnológicos da Região Nordeste do Brasil. A cidade possui uma agenda cultural variada, destacando-se os festejos de São João (chamado de "o maior São João do mundo"). As principais atividades econômicas são a extração mineral, culturas agrícolas, pecuária, indústrias de transformação, de be neficiamento, comércio varejista, atacadista e serviços, com importanterededeeducação esaúde, sendo destaque nacional na área de informática.

Conforme informações do M inistério da Saúde, ocorreram em Campina Grande, em 2005, 2.201 óbitos por todas as causas. A taxa de mortalidade infantil foi de 23,7 por 1.000 nascidos vivos no município, no mesmo período. A esperança de vida ao nascer encontra-se em torno de 70,5 anos ${ }^{11}$.

Com relação à inserção de Campina Grande no cenário da saúde, o município sedia o 30 Núcleo Regional de Saúde, unidade da divisão geopolítica administrativa estadual, constituindo-se numa macrorregional de saúde que congrega setenta municípios, sendo referência em serviços de saúde, ainda, para os estados de Pernambuco e Rio Grande do N orte. Encontra-seem Gestão Plena do SistemadeSaúdedesde 1997. Sua rede deserviçoséconstituída de dois hospitais públicos, doze hospitais privados, sete centros de saúde, oito unidades básicas de saú de e quarenta unidades básicas da saúde da família, onde atuavam, à época do estudo, cinquenta equipes do PSF, e dezesseis unidades-âncora, em 24 bairros, nos três distritos rurais e em 94 comunidades. No PSF, estão cadastradas 31.672 famílias, que representam 123.207 pessoas, com cobertura de $34 \%$ da população urbana e $100 \%$ na zona rural ${ }^{12}$.

A pesquisa desenvolveu-se em duas Unidades Básicas de Saúde da Família (UBSF), uma da zona rural e uma da zona urbana. A escolha por essas localidades distintas se deu de forma intencional, considerando a disparidade de desenvolvimento entre tais áreas. Foram, então, sorteadas duas, entreas unidades existentes em cada modalidade, que são identificadas no trabalho como UBSF U (urbana) e UBSF R (rural).

Compuseram a amostra doze profissionais, de todas as categorias que atuavam nas equipes sorteadas e que prestavam assistência à criança menor de um ano, eque desejaram participar da pesquisa, após as informações sobre o estudo e a assinatura do termo de consentimento livre e esclarecido. 0 estudo seguiu, rigorosamente, as normas da Declaração de H elsinki e as diretrizes da Resolução 196/ 96, do Consel ho Nacional de Saúde ${ }^{13}$.

$N$ a perspectiva de identificar o cuidado prestado pelos profissionais do PSF à criança menor de um ano, utilizamos como instrumento as oficinas deexpressividade, criatividadeesensibilidade ${ }^{14}$. Foi de fundamental importância a escolha das ofici- 
nas para a coleta de dados, pois a pesquisa é um ato de cuidado e, como tal, possibilita evidenciar as preocupações com a prática cotidiana e comportar questões mais amplas sobre instituições políticas e sociais, levando os profissionais a uma reflexão sensível eação criativa sobre a formação e a prática profissional no cuidar da criança menor de um ano ${ }^{15}$. Utilizamos, ainda, um roteiro de observação participante.

Em novembro de 2005, realizamos três oficinas, cada uma constituída pel as fases de apresentação, integração, relaxamento, descontração, desenvolvimento da temática, incluindo reflexão, discussão e síntese do material produzido. Todo processo foi fotografado e os discursos foram gravados em fitas cassetes, após autorização dos envolvidos.

0 material produzido foi tratado segundo a técnica de análise de conteúdo ${ }^{16}$. Por fim, constituímos um quarto encontro para a discussão, apre sentação e validação dos resultados com os atores envolvidos.

\section{Resultados ediscussão}

\section{A equipe do cuidado no PSF}

Os participantes foram 01 médica, 02 enfermeiras, 02 auxiliares de enfermagem, 02 assistentes sociais, 02 agentes comunitárias de saúde, 02 recepcionistas e 01 fisioterapeuta.

Os profissionais tinham idade entre 20 e 45 anos, sendo onze do sexo feminino e apenas um do sexo masculino. 0 tempo de atuação no PSF variou entre um etrês anos de serviço. Na divulgação dos resultados, os mesmos estão identificados pela função que executam na equipee pela unidade (rural ou urbana) à qual pertencem.

Um aspecto observado e que merece destaque refere-se à insuficiência de recursos humanos nas equipes.As unidades não possuem equipe de referência ou matricial. 0 fisioterapeuta da UBSR é funcionário de outro setor da Secretaria M unicipal de Saúde e encontra-se prestando serviço por decisão pessoal no PSF. As assistentes sociais atendem a mais de uma equipe e/ou unidade. Quando da coleta de dados, a equipe da zona urbana estava sem médico há seis meses ${ }^{17}$.

\section{O ambiente do cuidado no PSF}

As UBSF pesquisadas estão localizadas em regiões do município bastantecarentes esofrem problemas semelhantes, como fome e desemprego. Porém, a situação da zona rural é mais precária, principalmente com relação ao saneamento bási- co, pavimentação de ruas e condições socioeconômicas. Estas unidades funcionam em casas alugadas, com cômodos pequenos e adaptados. As paredes estão descascadas, pintadas a cal, o piso em cimento e o forro de algumas salas é feito de prémoldado, outras de gesso. Na UBSF rural, há salas cobertas com telhas de barro.

Sobre as instalações físicas, observamos que as unidades não traduzem um ambiente acolhedor, em que o usuário se sinta respeitado e valorizado. $\mathrm{N}$ ão existe ambiente próprio para 0 atendimento da criança, não há clima infantil. Para o M inistério da Saúde, a ambiência éum dosfatores-chave para 0 acolhimento do usuário ${ }^{18}$. A distribuição da estrutura organizacional e as modalidades de utilização do espaço físico devem atender aos aspectos sociotécnicos dos serviços e às necessidades dos sujeitos ${ }^{19}$. A inadequação das instalações físicas das unidades básicas estudadas contrapõe-se com 0 compromisso técnico-ético-político do PSF deprestar uma atenção humanizada e de qualidade ${ }^{9}$.

Com relação aos instrumentos de trabalho para o cuidado com a criança, as unidades estão equipadas com material básico para triagem, consultas e al guns procedimentos terapêuticos. Convém ressaltar queas instalações físicas e instrumentais da unidade da zona urbana são bem melhores do que as da zona rural. Ainda assim, nesta unidade, osarmáriosnão possuem portas, o bebêéexaminado numa mesa ginecológica, ondetambém seexaminam adultos e idosos, e não há brinquedos para auxiliar este exame. Na UBSF rural, a enfermeira levou alguns brinquedos para a sua sala de consulta.

0 caráter do cuidado à criança menor de um ano tem sido essencialmente técnico e normativo, as ações desenvolvidas são aquelas preconizadas M inistério da Saúde ${ }^{20}$. Quanto à sistematização do cuidado, a assistência é feita através da clínica pediátrica e da puericultura. 0 acompanhamento de puericulturaémensal, agendado, mas 0 atendimento é por ordem de chegada, não se utilizando, ainda, o acolhimento com classificação de risco, que ordena 0 acesso pela prioridade da situação e não como fila de supermercado ${ }^{18}$. U tiliza-se uma ficha de avaliação própria do programa e a caderneta de saúde da criança. Entretanto, não há esquema metodológico específico para avaliação do desenvolvimento neuropsicomotor.

\section{Um ser a ser cuidado}

A análise dos discursos dos profissionais permitiu apreender que o cuidado à criança é inegavelmente necessário para a sua sobrevivência, como expresso no discurso: Porque toda criança precisa de cuidado, como uma planta precisa, e, se 
ninguém liga para ela, ela acaba morrendo. (Enfermeira UBSF R)

A sobrevivência é a finalidade mais elementar da criatura humana. É apenas a condição para que se realizem finalidades mais gerais, inclusive o gradual amadurecimento das capacidades orgânicas e psíquicas. É imperativo pensar em algo mais elevado, ou seja, sua realização como um ser desejante, útil e social e, portanto, merecedor do melhor que podemos Ihe dar ${ }^{4}$.

Vieira e Prado ${ }^{21}$ associam o alto custo desta dependência a um artifício necessário para o efetivo domínio das complexidades da comunidade social humana. Durante a realização das oficinas, a importância da mãe nesta tarefa foi abordada pelos participantes deste estudo, em várias ocasiões. Destacamos, como exemplo, o seguinte fragmento: $M$ as para esta criança ser bem cuidada, ter este desenvolvimento, tudo tem a ver com a mãe. ( $A$. Social UBSF U)

O reconhecimento da importância do vínculo mãe bebê para a constituição psíquica do bebêe 0 seu desenvolvimento é ponto pacífico ${ }^{22}$. Entretanto, não podemos deixar de atentar para o fato de que, nos casos das mães do PSF (mulheres de baixa renda, de baixa escolaridade, com déficit alimentar, péssimas condições de moradia, etc.), esta relação com o bebêpodeestar distante do idealizado. Compete aos profissionais que acompanham a mãe e a criança observar como vem se dando essa relação etentar apoiar eintervir sobre as questõesidentificadas4.

Assim, muitas crianças estão sendo concebidas e se desenvolvendo em ambientes hostis e, por serem sensíveis, tudo as afeta. Como o bebê ainda não sabe queixar-se de seus incômodos e de suas aflições, o corpo éo primeiro veículo a sentir diretamente qualquer estímulo ou invasão vindos de fora. Distúrbios de sono e de alimentação, tristeza, ansiedade, problemas de pele, alergias, atraso no desenvolvimento, entre outros, podem não ter qualquer origem orgânica²3.

$\mathrm{Na}$ criança, não há uma correspondência biunívoca do tipo "determinado sinal, tal distúrbio", mas sim uma hipótese importante de que, a partir daí, podem surgir transtornos para o desenvolvimento da criança ${ }^{24}$. É através da linguagem nãoverbal, própria do bebê, que el e expressa seus estados de bem e mal-estar ${ }^{17}$.

Abordando o perfil das crianças da área de trabalho, a recepcionista da U BSF U lamentou: Lá, às crianças, faltam carinho de mãe, de pai. São bem tristinhas, na realidade.

As crianças devem ter o melhor início da vida, precisam de alimentação, de abrigo, de cuidados afetivos para se constituir como um ser de desejo e ter um desenvolvimento saudável. Para muitas destas crianças, assistidas pelos profissionais do PSF, além de carinho, toque, afago, falta comida, brinquedo, falta muita coisa, conforme pudemos observar nosdiscursos apresentados pelos profissionai ${ }^{17}$.

Em uma oficina, solicitamos que os participantes modelassem o bebê menor de um ano ou al go que o representasse. Uma profissional modelou uma gaiola e dois passarinhos, justificando: Porque eles gostam de brincadeira e moram num sítio, lá é uma serra, e só tem aquela casa, aí não convivem com outras crianças. A brincadeira é isso, passarinho [pausa, choro], com ele lá mesmo, não tem outras crianças, outro tipo de brinquedo, não tem. É só com isso. (ACS UBSF R)

Destacamosno depoimento a sensibilidadeque a participante demonstra ao retratar a realidade destas crianças, quando consegue visualizar a precariedade de vida social e econômica a que estão submetidas. Para a ACS, a importância do brincar é tão relevante para a criança que ela associou os passarinhos ao brinquedo a que essas crianças não têm acesso e representou as precárias condições sociais - limitantes - como uma gaiola.

Há, atualmente, no nosso país, cerca de 23 miIhões de crianças com até 6 anos de idade ${ }^{25}$. $\mathrm{N}$ ada menos que $45 \%$ destas crianças são pobres e, portanto, vivem em péssimas condições de vida, estando longe de terem seus direitos básicos respeitados no cotidiano, como mostra a fala a seguir: Há criança com bastante piolho, barriga também bastante crescida, mas a minha preocupação maior é ondeesta criança está, no seio desta família?É onde tem violência, desemprego, fome, uma série de indicadores. $\mathrm{E}$ a gente com uma responsabilidade bastante grande, talvez por não ter sido feito pelos governantes, a gente hoje está lá na ponta e está preocupado realmente, qual éa resposta que a gente tem dado? ( A. Social UBSF U)

Em muitas outras enunciações, os profissionais retrataram o estado de pobreza que eles têm encontrado nas crianças e fizeram uma alusão à origem dos problemas: A gente sabe que, por trás, tem um monte de problemas, o pai não quer assumir, tem a violência intrafamiliar, e que tudo isso vai repercutir na criação desta criança, no dia-adia. Falta de emprego, condições de moradia, tudo isso a gente vê. (Enf. UBSF U)

Há possibilidade de a criança adoecer e morrer, como também apresentar atrasos em seu potencial de crescimento, desenvolvimento e constituição psíquica, devido aos efeitos negativos de condições econômicas epsicossociais adversas, fato que tem sido objeto de inúmeros estudos nas últimas décadas 4 . 0 discurso da profissional a seguir convoca a um olhar sobre o contexto em que a 
criança vive: Às vezes, a criança está ali, mas é importantenessemomento conhecer a família, vai identificar real mente o que está acontecendo naquela família. Com aquela pessoa, nada acontece isolado, enfim, é o contexto todo, família, comunidade, uma série de coisas. (A. Social U BSF U)

Os profissionais traçaram um quadro complexo, onde preponderam as más condições de vida, associadas à privação dos direitos básicos, que vêm corroborar na gênese dos problemas de saúde. Assim, cuidar da criança menor de um ano não significa lutar apenas contra as doenças infecciosas, combater as principais causas da desnutrição, tratar as doenças prevalentes da infância, mas também cuidar da desilusão, da discriminação, da injustiça, da solidão ${ }^{17}$. Cabe lembrar que os profissionais na estratégia Saúde da Família devem estabelecer uma relação de proximidade, pelo pressuposto da formação de vínculos e responsabilização social que o programa orienta9.

Tem-se visto que, com o cuidado que vem sendo prestado à saúde da criança, doenças têm sido erradicadas, a taxa de mortalidade tem diminuído e as oportunidades de realização parecem ter se ampliado; mas, por outro lado, ainda existem crianças em situação de miséria e expostas a condições de risco.

A avaliação de indicadores socioeconômicos, ambientais e demográficos é de fundamental importância no cuidado à criança. Há consenso em relação à importância, no primeiro ano de vida, da qualidade dos cuidados recebidos e da influência do ambiente para seu desenvolvimento ${ }^{7}$. Quanto mais jovem a criança, mais vulnerável é ao seu ambientefísico e social. I sso faz com que as condições favoráveis se dêem em função de cuidados gerais, como o tempo, a atenção, o afeto da mãe, da família e da sociedade, e dos recursos materiais einstitucionais como alimentação, moradia, saneamento, serviços de saúde, entre outros. Entretanto, tempo, atenção e afeto, quando maximizados, permitem a otimização dos recursos materiais e institucionais de que a criança dispõe ${ }^{23}$.

Segundo Waldow ${ }^{26}, 0$ ato de cuidar sempre esteve presente na história da humanidade, mas "o ser humano apresenta paradoxos e ambiguidades nos comportamentos de cuidado como comportamentos de não-cuidado". Estes extremos são observados no comentário: Eu fiz esta bonequinha aqui, ela é escurinha, não pela cor da pele, mas pelo meio que ela vai se desenvolver. É um bebê que não tem condições, é uma criança que não recebe o cuidado da mãe, sem afeto. Condições precárias de moradia, de viver, de um modo geral. Então eu fiz aqui uma criança largadinha, sem rosto, sem muita perspectiva, enquanto esta outra aqui também, fiz clari- nha, mas não pela questão da pele, mas uma criança bem cuidada, bem alimentada, uma criança quetem muito amor. Então uma criança saudável, que ela brinca, sorri sempre, não é? (Enf. UBSF U)

Nesta declaração, há uma descrição de que a criança que é cuidada está arrumadinha, senta, brinca, é saudável, éfeliz eébranca, ou seja, está se desenvolvendo bem. A criança que não é cuidada sem rosto, largada, escura - não está se desenvolvendo, está sem semblante, parece não ter vida. Outro aspecto que nos chamou atenção nesta fala refere-se ao preconceito racial, que, embora não assumido pela informante, está embutido no seu discurso no momento em que representa a criança descuidada com pele negra e a cuidada com pele branca. Sabe-se que o preconceito pode negligenciar ou interferir na relação de cuidado que é essencial para um bom desenvolvimento ${ }^{17}$.

$\mathrm{Na}$ assistência à sua saúde, cabe aos profissionais entender que a criança precisa e merece uma assistência que promova a vida eque não podemos postergar as dificuldades e as necessidades da sua família. É através de um cuidado que interprete e atenda às necessidades esolicitaçõestanto da criança como também de todos que a cercam que faz com que ela vá aumentando, progressivamente, 0 autocontrole sobre o seu próprio corpo e sobre os seus sentimentose, pouco a pouco, vá conseguindo lidar com as demandas do seu cotidiano ${ }^{4}$.

\section{O cuidado que temos}

Como frisamos, o bebê humano constitui-se subjetivamente na relação com o outro, embora tenham sido saudáveis as condições de gestação e de nascimento. Este modo o torna singular e especial, porque 0 aparato simbólico que precisa ser instalado vai sempre depender do outro. No primeiro ano de vida, o bebê está em pleno processo de maturação das estruturas anátomo-fisiológicas, de crescimento corporal, de aquisições instrumentais fundamentais quanto à linguagem, psicomotricidade e aprendizagem; é também o período em que se operam as primeiras inscrições psíquicas4.

Desta forma, o processo de cuidar da criança não deve se pautar somente na identificação dos sinais esi ntomas clínicos da doença, na verificação dos marcos tradicionais do desenvolvimento, mas nas nuances e modificações que ocorrem na sua estrutura psicofísica, as quais abalam a sua totalidade. 0 cuidar envolveumaação interativa, implica a percepção da globalidade, da transdisciplinaridade e uma atenção séria e responsável do ser cuidador para o ser cuidado.

$\mathrm{N}$ a oficina de modelagem, verificamos que vários participantes apresentaram dificuldades em 
modelar a criança menor de um ano. Sua produção estética foi uma criança com bem mais idade. No entanto, uma profissional que modelou um bebê e fez-lo sem rosto confessou: Q uando você falou "quem é esta criança de que você cuida?", na realidade, eu fiquei imaginando, eu não consegui ver o rosto das crianças menores de três meses, mas lembrei de todas as mães. (Enf. UBSF U)

Ao ser indagada sobre seu relato, foi enfática: Acho que, na hora, você presta mais atenção, dá mais atenção à mãe, evocêfaz aqueleexame, percebe a expressão da mãe, como ela é.

A profissional justifica-se dizendo que, muito presa ao que é técnico e normativo (medir, pesar, orientar a mãe sobre a amamentação), não tem estabelecido uma relação interativa com o bebê. Uma relação em que a cuidadora desempenha seu trabalho de forma correta, eficiente, porém preocupada apenas com o aspecto técnico, é muito frequente ${ }^{10}$. Consideramos este cuidar que robotiza as ações, apesar derotineiro, muito conflitantecom os princípios humanísticos que regem o $\mathrm{PSF}^{9}$. Entretanto, sabemos, também, quenão um único PSF, que cada município, gestor ou equipe, muitas vezes, não operam a estratégia como apresentada pelo M inistério, por falta de capacitação, recursos humanos, infra-estrutura adequada, questões político-partidárias, entre tantas.

A importância das relações interpessoais, da anterioridade do outro na vida do bebêe das intervenções afetivas e efetivas favorecem a estruturação e o desenvolvimento de uma identidade própria. Antes de se perceber como pessoa, o bebê tem primeiro a percepção do outro quevai servindo deespelho para ele. A confiança, a dor, o prazer, a exploração do espaço, a percepção e a expressão se estruturam a partir desta relação, da mesma forma que sua função de comunicação é instaurada à medida que 0 outro dáa seus gestosesinaisuma leitura esignificação. Sua capacidade de despertar o interesse do outro e o retorno a este interesse é o que o faz constituir-se como um indivíduo, um ser de desejo $0^{4}$.

No discurso da mesma enfermeira, as competências do bebê também não foram consideradas. Este fato evidencia-se na complementação do seu discurso: Realmente, não, não lembrei de nenhum rostinho da criança menor de três meses, até porque a criança paradinha, não é? E quando vocêtem uma criança maior, que você bota no colo, você brinca com ela e ela ri.

0 investimento na construção da subjetividade do bebê e a valorização de suas competências pelo profissional de saúde é uma das principais condutas no cuidado ao menor de um ano. Tal atitude servirá, inclusive, de referência para muitos pais, que, presos a uma concepção antiga de encarar 0 bebêcomo sujeito passivo, de aparência frágil edependente, desprendem atitudes superprotetoras ${ }^{17}$.

$\mathrm{N}$ a tentativa de identificar quais os instrumentos e estratégias os profissionais usam na prática diária para desenvolver suas atividades, utilizamos, em outra oficina, duas mesas grandes, com cerca duzentas sugestões de materiais úteis a este cuidado, como protocolos de avaliação, estetoscópio biauricular, termômetro, brinquedos, roupinhas de bebê, material de higiene, livros, folhetos, chupetas, mamadeiras, remédios e outros produtos. N ossa intenção foi instigar a imaginação ea criatividade dos sujeitos.

Solicitamos aos profissionais que escolhessem objetos relacionados ao cuidado da criança, justificando, posteriormente, suas escolhas. As enfermeiras, as auxiliares de enfermagem e as agentes comunitárias escolheram as fichas de acompanhamento (peso e altura, desenvolvimento e vacinação) e frisaram que os instrumentos escolhidos também eram utilizados por outros membros da equipe, como refere este discurso: Eu escolhi isto porque, todo mês, não só o médico e a enfermeira se preocupam com a altura eo peso da criança, como a gente também. (ACSUBSF U)

No entanto, a médica da zona urbana, falou: Bom, eu escolhi, basicamente, três coisas mais relacionadas mesmo à parte médica. 0 livro, onde vai tratar das patologias médicas; o estetoscópio, para auscultar o bebê; e, aqui, a curva do crescimento e desenvolvimento do bebê.

Este depoimento nos remeteu à obsoleta visão do papel do médico como central e hegemônico, essencialmente técnico e mediado por instrumentos. Esta visão contraria a nova demanda que o processo de trabalho do PSF coloca para os profissionais, que é o trabalho em equipe?.

A preocupação dos profissionais com 0 acompanhamento do crescimento e do desenvolvimento ressonou como o norte que a equipe tem para este cuidado. Porém, em nenhum momento, foi feita alusão à necessidade de orientações antecipatórias com relação ao desenvolvimento, e até mesmo ao cuidado, com a detecção de sinais de alerta para distúrbios do desenvolvimento e da constituição psíquica, principalmente pelo risco social a que estão submetidas. Esta constatação corrobora que a detecção de tais si nais para transtornos na constituição psíquica e no desenvolvimento neuropsicomotor e o pronto encaminhamento para intervenção precoce ainda não estão acontecendo como deveriam ${ }^{4}$.

Outro material bastante escolhido foram os brinquedos, principalmente pelos membros da equipe da zona urbana, em cuja unidadenão existe nenhum sequer. A médica desta equiperelatou sen- 
tir muita dificuldade no exame da criança devido a sua falta: Algum brinquedinho, algum instrumentozinho, um chocalhinho, alguma coisa para o bebê mesmo, até para fazer exame, aí eu faço até uma zoadinha, alguma coisa para ver se o bebê olha de um lado para outro. E, assim, para ver um sorriso, alguma percepção dele.

Ainda nestadinâmica, como em outrosmomentos das oficinas, muita ênfase foi dada aos materiais de higiene. Os profissionais comentaram sobre as dificuldades que as mães têm de possuir fral das descartáveis, perfumes, sabonete e sobre a negligência materna neste cuidado, devido às questões culturais. Podemos então deduzir que, acima de toda e qualquer lógica, ou não-lógica, para muitos dos profissionais estudados, o cuidado está muito ligado à questão da higiene, como também há uma conotação de cuidado compreendido como exterioridade, beleza, cheiro, com valores que são superficiais em relação ao processo de cuidado ${ }^{27}$. Sabemos que muitas doenças são consequências da falta de higiene. M as, para estar limpo, necessariamente, não é preciso um perfume ou uma fralda descartável. 0 cuidar requer mais que tão-somente higiene e limpeza; demanda condições dignas de vida.

Com relação à imunização, a equipe demonstrou usar todo equalquer recurso para prover este cuidado, como, por exemplo, acionar o Conselho Tutelar quando as mães resistem, ou até levar a vacina na casa daquelas crianças cujas mães estão trabalhando. Referindo-se, ainda, à imunização e às estratégias utilizadas para este cuidar, reportamo-nos ao discurso da auxiliar de enfermagem da zonaurbana, quando se referiu à chupeta que construiu junto ao bebê na oficina de modelagem: $A h$ ! Aqui é uma chupetinha que, infelizmente, não é muito [pausa] mas as crianças gostam!

Sua pausa foi acompanhada por uma expressão de indecisão ou temor. Quando indagada do porquê, afirmou: Quando se dá [a chupeta], as bichinhas num instante se calam, quando se dá vacina.

Duas dimensões do senso comum norteiam as ações maternas de incluir a chupeta nos pertences do bebê. A primeira, diz respeito ao aspecto prático e utilitário; ele pode precisar deste artefato e a mãe já está preparada; a segunda aponta para a representação simbólica, que eleva a chupeta ao status de complemento da figura da criança e de instrumento para acalmá-la.

Muitos trabalhos mostram associação do uso da chupeta com a diminuição do tempo de amamentação eas instituições que norteiam a Iniciativa Hospital Amigo da Criança têm proibido a sua oferta. $O$ uso da chupeta écriticado por uns eindicado por outros. Estudos encontrados na literatu- ra atual não foram desenvolvidos, especificamente, para testar a associação da chupeta e a abreviação do tempo de amamentação, mas sua utilização tem sido combatida, considerando-se os efeitos deleté rios para a saúde da criança, como problemas odontológicos e fonoaudiológicos ${ }^{28}$. Há controvérsias se, utilizada racional mente, podeestimular a atividade muscular e ter influência benéfica na saúde oral do bebê e no desenvolvimento dos arcos osteodentários, além de satisfação na necessidade de sucção, sem interferir na atividade de sucção nutritiva. Concordamos com os autores, quando afirmam que as consequências dependerão da frequência, intensidade eduração do uso, e com Klajner ${ }^{29}$, quando diz não ver nenhum inconveniente em continuar seu uso até um ano de idade. A justificativa usada pelos autores é que, no primeiro ano de vida, há uma necessidade latente de sugar.

Outro ponto enfatizado foi a amamentação exclusiva, ressaltada com unanimidade como a grande resistência que as mães têm em aleitar. Nos depoimentos, este aspecto é representado como sendo "a mamadeira o grande problema que eles enfrentam": 0 grandeproblema nosso - a mamadei$\mathrm{ra}$, quea gente passa tanto tempo falando com a mãe, desde o pré natal, quea gente insiste para não dar a mamadeira. "M ãe, dá o peito", como estimular a mama, como proteger, nasce o bebê. Então, éo grande vilão desta história toda de cuidar da criança. Eu acho que o grande problema do nosso cuidar da criança é o uso da mamadeira. (Enf. UBSF U)

O fato de a mãe comprar a mamadeira também é visto como uma questão cultural, pois acha que um dia vai usar e, como qualquer outro acessório básico do bebê, a mamadeira faz parte do seu enxoval, como veremos neste exemplo: Quando a gente chega na casa da puérpera, é lá em cima do móvel, uma mamadeira, ou queganhou ou quea mãe já comprou, porque sabeque vai usar. (Enf. UBSF U)

Muitos outros instrumentos foram escolhidos e estratégias foram apresentadas, como o cuidado com o planejamento familiar, com a retirada do registro civil, com a providência de órteses. Um dos grandes desafios com o quais os profissionais do PSF têm se deparado diz respeito à capacidade de integração com a rede do sistema de saúde. Essa integração pressupõe a organização de um sistema dereferência e contra-referência, com fluxos epercursos definidos, organizado de acordo com a demanda populacional. No dia-a-dia, estes profissionais não têm vivido a garantia deste acesso, como demonstra esta fala: A gestante ganha neném e a ultra-som vem depois. (Aux. de Enf. UBSF R)

A dificuldade na operacionalização do cuidado, não apenas no aspecto quantitativo, mas tam- 
bém na qualidade da atenção que deve ser ofereci$\mathrm{da}$, produz, com certa frequência, uma descontinuidade da assistência e, consequentemente, um sentimento de impotência e de desilusão por parte dos profissionais.

\section{O cuidado de que precisamos}

Durante todo o percurso da pesquisa, sentimos e constatamos, através do dito e do não-dito, que os profissionais apresentavam-se despreparados, física, mental, intelectual e socialmente para este cuidar, ou seja, estavam precisando ser cuidados. Através desta identificação, surgiu o tema da última oficina: "Sensibilizando o cuidador para o cuidado". Este momento foi constituído por leituras de textos, dinâmicas de toque, massagem para os pés, relaxamentos, entre outras abordagens. $N$ as discussões afloradas, os profissionais, preocupados com o seu compromisso ético e moral de prover "um olhar vigilante e uma ação cuidadora", lamentaram, entre outras dificuldades, a insuficiente formação trazida da academia e a falta de um processo de capacitação e educação permanente para atuar na Estratégia Saúde da Família e atender ao dinamismo que o cuidado à criança menor de um ano requer: Realmente, a gente não pode ficar sem treinamento para a criança menor de um ano. Eu, pelo menos, o quefaço éo que aprendi na universidadeealgunscursosquea gentefaz, maslá em termosde secretaria. (Fisiot. UBSF R)

Com o compromisso profissional, moral e ético de prover maior parceria entre a academia e os serviços de saúde, como professores da universidade, propusemos um curso de capacitação sobre o cuidar da criança menor de um ano, e a proposta foi aceita, sendo ressaltada pelos participantes a urgência de sua real ização.

O cuidado com a criança não é propriedade ou mérito desta ou daquela instituição ou responsabilidade exclusiva da esfera governamental. Este cuidado transcende a esfera individual, que elegevaloresuniversais eexigeque extrapolemos o eu eo nós, em busca do juízo universalizável, no qual os meus interesses valem tanto quanto os seus, e os nossos tanto quanto os vossos. Estamos carentes de uma ética pelo viés do cuidado. 0 ato de cuidar não é somente emoção, preocupação, atitude ou boas intenções. Ele é amplo, complexo e requer ações concretas em dimensões humanísticas, sociais, éticas, biológicas e espirituais, em todos os locais em que se presta este cuidado.

\section{Conclusão}

Ainda convivemos com uma gama de problemas que alteram a capacidade dos serviços de saúde de operar de forma eficaz a demanda por saúde na vida de nossas crianças, o que pode ser detectado por meio da pouca efetividade das ações de promoção, prevenção e recuperação e, consequentemente, altos índices de morbidade e mortalidade infantil.

O PSF surgiu como uma estratégia estruturante, criando uma ossatura para um modelo de atenção universal, integrativo, equitativo, humanizado e, acima de tudo, resolutivo. No entanto, um dos limitantes deste processo éa ausência deferramentas para a instrumentalização daqueles que se dedicam a este fim. A Estratégia Saúde da Família, para melhorar 0 acesso e a qualidade da atenção prestada, requer, dentreoutros pontos, queas ações e serviços prestados no cuidado à criança menor de um ano sejam garantidas com capacidade instalada, aquisição e manutenção de equipamentos com tecnologias adequadas ao bom atendimento, investimento dos recursos humanos euma definição de uma política intersetorial capaz de contribuir para a melhoria da qualidade de vida.

O sucesso de muitos serviços básicos de saúde tem sido atribuído ao desempenho de suas equipes, que, na tentativa de superar tantas dificuldades, têm juntado às condições de trabalho uma pitada da alma, não raras vezes, extrapolando suas próprias condições humanas. Admiramos estes atos e, ao mesmo tempo, tememo-los. Para o cuidado humano, éimprescindível a delicadeza, a gentileza, a disposição, a amorosidade, mas tudo isso, sem o conhecimento científico, a estabilidadeemocional e o suportetécnico-gerencial einstrumental necessário, acarretará ações e serviços que não vão produzir nas crianças, principalmente naquel as menores de um ano, o efeito de um cuidado capaz de suprir suas necessidades biológicas, físicas, emocionais e intelectuais.

Afirma-se que a filosofia de apresentar a estratégia Saúde da Família não foi a de construir uma medicina pobre para pobres, mas, de acordo com o que conferimos e apresentamos, embora de maneira bastante sucinta, há um equívoco nesta afirmação. Entendemos que grande parte dos problemas evidenciados neste estudo podem ser resolvidos com ações simples e de baixo custo. Falta uma política de gestão comprometida com a efetiva mudança. Contudo, temos também ciência de que muitos problemas de saúde não podem ser resolvidos no interior do programa, dependem de políticas que promovam melhores condições de vida. 


\section{Colaboradores}

EM Vasconcelos participou da concepção, delineamento, análise, interpretação e redação do artigo, M FA da Silveira participou do delineamento, análise, interpretação e redação do artigo, M C Eulálio participou da revisão crítica e aprovação da versão para publicação ePFV M edeiros participou da revisão crítica e aprovação da versão para publicação.

\section{Referências}

1. Ariès P. História social da criança e da família. $2^{\text {a }}$ ed. Rio de Janeiro: Editora Guanabara; 1986.

2. Orlandi OV. Teoria e prática do amor à criança: introdução à pediatria social no Brasil. Rio de Janeiro: Jorge Zahar Editor; 1985.

3. Santos Junior HPO, Silveira MFA. 0 processo de desinstitucionalização da atenção em saúde mental no município: visão dos profissionais sobre a experiência da residência terapêutica. Campina Grande: Universidade Estadual da Paraíba; 2007.

4. Jerusalinsky J. Enquanto o futuro não vem: a psicanálise na clínica interdisciplinar com bebês. Salvador: Álgama; 2002.

5. Cecilio LCO, Lima M HJ. Necessidades de saúde das pessoas como eixo para a integração de equipes e a humanização do atendimento na rede básica. In: Pimenta $A L$, organizador. Saúde e humanização: a experiência de Chapecó. São Paulo: Hucitec; 2000. p. 159-182.

6. Focault M. Microfísica do poder. 4a ed. Rio de Janeiro: Graal; 1984.

7. Marcondes E, Vaz FAC, Ramos JLA, Okay Y. Pediatria básica. 9a ed. Tomo I. São Paulo: Savier; 2002.

8. Collière MF. Promover a vida: da prática das mulheres de virtude aos cuidados de enfermagem. Lisboa: Sindicato dos Enfermeiros Portugueses; 1989.

9. Brasil. M inistério da Saúde. Saúde da Família: uma estratégia para a reorientação do modelo de atenção. Brasília: M inistério da Saúde; 1997.

10. Waldow VR. Cuidado humano - 0 resgate necessário. 3a ed. Porto alegre: Sagra Luzzatto; 2001.

11. Brasil. M inistério da Saúde. Estatísticas Vitais 2005 [acessado 2008 abr 04]. Disponível em: http:// www.datasus.gov.br

12. Farias AFM R. Vivências de sofrimento e prazer no trabaIho: a dor e a delícia de ser trabalhador da Saúde da Família em Campina Grande-PB. [dissertação]. Campina Grande (PB): U niversidade Estadual da Paraíba; 2005.

13. Brasil. Resolução 196, de 10 de outubro de 1996. Dispõe sobre as diretrizes e normas regulamentadoras de pesquisa envolvendo seres humanos. Diário O ficial da União 1996; 16 out.

14. Gauthier JHM, Cabral IE, Santos I, Tavares CM M . Pesquisa em enfermagem: novas metodologias aplicadas. Rio de Janeiro: Guanabara Koogan; 1998.

15. Silveira MFA. A Sagração das Flores: um ritual para encantar o corpo da mulher no cuidado [tese]. São PauIo (SP): Escola de Enfermagem, Universidade de São Paulo; 2001.
16. Bardin L. Análise de conteúdo. Lisboa: Edições 70; 2006.

17. Vasconcelos EN. O cuidar da criança menor de um ano no PSF: discurso e prática dos profissionais de saúde [dissertação]. Campina Grande (PB): Universidade Estadual da Paraíba; 2006.

18. Brasil. M inistério da Saúde. Política Nacional de Humanização. Braślia: M inistério da Saúde; 2004.

19. Ferreira MC, M endes AM. Só de pensar em vir trabaIhar, já fico de mau humor!: atividade de atendimento ao público e prazer e sofrimento no trabalho. Rev. Estudos de Psicologia 2001; 6(7):93-104.

20. Brasil. M inistério da Saúde. Agenda de Compromisso para a Saúde Integral da Criança e Redução da M ortalidade Infantil. 2a reimpressão. Série A. Normas e M anuais técnicos. Brasília: Ministério da Saúde; 2005.

21. Vieira ML, Prado AB. Abordagem evolucionista sobre a relação entre filogênese e ontogêne no desenvolvimento infantil. In: Moura MLS. 0 bebê do século XXI e a psicologia em desenvolvimento. São Paulo: Casa do Psicólogo; 2004.

22. Brun EHM, Schermann L. Vínculos iniciais e desenvolvimento infantil: abordagem teórica em situação de nascimento de risco. Cien Saude Colet 2004; 9(2):457-467.

23. Brasil. M inistério da Saúde. Departamento de Atenção Básica. Saúde da Criança: A companhamento do crescimento e desenvolvimento infantil. Brasília: Ministério da Saúde; 2002.

24. Camarotti MC. Atendimento ao bebê - uma abordagem interdisciplinar. São Paulo: Casa do Psicólogo; 2001.

25. UNICEF. Situação da criança brasileira. [site da Internet] 2006. [acessado 2006 ago 27]. Disponível em: http:// www.unicef.org.brazil/sib06.htm

26. Waldow VR. 0 cuidado na Saúde - as relações entre 0 eu, o outro e o cosmos. Petrópolis: Vozes; 2004.

27. Vigarello G. 0 limpo e o sujo. São Paulo: Martins Fontes; 1996.

28. Sertório SCM, Silva IA. As faces simbólica e utilitária da chupeta na visão das mães. Rev. Saúde Pública 2005; 39(2):156-162.

29. Klajner H. A auto-estimulação precoce do bebê. $3^{\text {a }}$ ed. São Paulo: M arco Zero; 1998.

Artigo apresentado em 05/10/2008

Aprovado em 25/06/2007

Versão final apresentada em 12/08/2007 